\title{
Los arbitrios con fines no fiscales en el Decreto de 25 de enero de 1946
}

Con el antecedente del artículo 331 del Estatuto municipal y de los artículos 32 y 33 del Reglamento de Hacienda municipal de 23 de agosto de 1924, ha regulado el Decreto de 25 de enero de 1946 , en sus artículos $48,49,50$ y 51 , esta materia, retocando y mejorando el antecedente.

El concepto que el artículo 48 da de los arbitrios con fines no fiscales es más depurado y ajustado a la misión que aquellos han de cumplir. $\mathrm{Y}$ si bien recoge la expresión de su finalidad no se copia el precepto del artículo 31 del Reglamento de $\mathrm{Ha}$ cienda, pues lejos de afirmarse, como este artículo decía, que tales arbitrios se daban para "vencer las resistencias al cumplimiento de Ordenanzas de policía urbana o de otras disposiciones en materia sanitaria", reduce a sus justos límites la función de tales arbitrios, en cuanto sirven para "coadyuvar al cumplimiento" de tales Ordenanzas y disposiciones sanitarias, lo cual está en consonancia con el acertado precepto que se contiene en el párrafo $3 .^{\circ}$ del mismo artículo, del que más adelante me ocuparé con glosa más amplia.

El establecimiento de los arbitrios con fines no fiscales requiere, según nuestrc actual derecho positivo, determinadas condiciones que se exponen a seguido:

a) Finalidad. No pueden tener carácter fiscal, ni tender directamente a obtener un rendimiento económico. Este se producirá indirectamente en el caso de que los comprendidos en las normas no cumplan éstas. Pero su finalidad, la intención por 
que el Ayuntamiento se mueva a imponerlos no puede ser sino «evitar fraudes, mixtificaciones o adulteraciones en la venta de artículos de primera necesidad"; "coadyuvar al cumplimiento de las Ordenanzas de Policía Urbana y rural o de disposiciones en materia sanitaria"; "contribuir a la corrección de las costumbres" o "prevenir perjuicios a los intereses del Estado, Provincia o Municipio", conceptos de una gran amplitud en los que caben múltiples aplicaciones.

Pero es claro que no basta querer el fin; es necesario que la Administración halle la adecuación de medio, tiempo, lugar y cualquier otra circunstancia que permita apreciar en el acto de la Administración la prudencia y el buen criterio que debe presidir todo actuar de los órganos investidos de la potestad imperativa. Esto nos lleva a otra nota que deben tener y es la de

b) Congruencia. Los fines que persigue tal clase de arbitrios no se pueden alcanzar sino con medios que sean adecuados, oportunos, congruentes. Cuando en el acuerdo de imposición puedan advertirse signos de arbitrariedad, de inconsecuencia, de despropósito en la relación de medios a fines se dará la incongruencia que puede permitir una impugnación con éxito contra su imposición. Desde luego, resulta imposible dar normas fijas, pues razones de lugar, de tiempo, hasta de costumbres y usos locales pueden influir en la apreciación de si un medio es o no congruente para conseguir el fin propuesto.

c) Competencia. Resulta casi inútil destacar esta nota. Si el fin que se trata de conseguir no entra en la esfera de la competencia municipal, el Ayuntamiento no puede establecer un medio de coerción, como es el arbitrio con fin no fiscal, para obtenerlo. Es ciertamente muy amplio el ámbito de atribución de los Ayuntamientos, pues superado el principio de la especialidad que, procedente de la doctrina francesa dominaba en nuestra Ley del 77, hoy habrá de aplicarse con carácter extensivo según el sentido de la Ley de Bases de 17 de julio de 1945 (Base 11), que dice ser "de la competencia municipal el gobierno y administración de los intereses peculiares de los pueblos", y cuya actividad habrá de dirigirse a conseguir los fines que luego especifica en larga enumeración, por vía de ejemplo, ya que, 
por último, admite "cualesquiera otras obras y servicios que tengan por objeto el fomento de los intereses y de las aspiraciones locales de la comunidad Municipal».

No se eche en olvido que la competencia se halla determinada por razón de la materia y por razón del territorio (queda al margen la competencia interna funcional) y la falta absoluta de competencia para poner un acto hace que éste sea nulo.

d) Motivación. No se pueden establecer esta clase de arbitrios sin que se expresen los motivos que mueven a la Corporación a tomàr el acuerdo de imposición. El artículo 31 del Reglamento de Hacienda establecía que cla Memoria que la Comisión Permanente redacte al someter al Ayuntamiento Pleno el proyecto de presupuesto, deberá contener explicación de los arbitrios con fines no fiscales que se establezcan, de los fines perseguidos con su institución y de las razones de todo orden que los motiven".

De modo que las razones que se tengan para su establecimiento han de hacerse constar expresamente, debiendo el acuerdo exponer el por qué de la imposición, y los fines que con ella se intentan obtener.

e) No lesionar injustamente intereses económicos le gítimos. Difícil es determinar el alcance de este precepto y precisar "a priori" cuándo se darán tales supuestos.

Desde luego toda lesión "injusta” debe ser descartada del actuar de la Administración, que ha de obrar de acuerdo con los dictados de la justicia, aun cuando ésta no tenga su expresión externa en el dèrecho positivo. Y esta injusticia no puede atentar a intereses económicos legítimos, ámbito demasiado estrecho de protección legal, pues no sólo los intereses ecunómicos son dignos del amparo del legislador sino cualquier otra clase de interés, y más acaso los intereses económicos son dignos del amparo del legislador sino cualquier otra clase de interés, y más acaso los intereses morales que los materiales.

Pero, ¿qué se. ha de entender por interés legítimo? El propietario que construyó conforme a unas determinadas ordenanzas en una alineación entonces prescrita ¿tiene un uinterés legítimo", o tiene algo más, un interés juridicamente tutelado, que 
diria Ihering, un derecho subjetivo que debe ser respetado por la Administración?

El propietario de una casa de viviendas que no tiene la altura de techos que una nueva concepción de la higiene y sanidad impóne para las de nueva construcción, ¿ puede ser obligado a satisfacer un arbitrio de carácter no fiscal? Si es principio fundamental de la Administración "quieta non movere" y el propietario tiene a su favor una situación jurídica nacida de haber construído según Ordenanzas, aunque las nuevas tendencias sanitarias impongan otras normas en las edificaciones, no puede desconocerse tal situación jurídica. Puede el interés general demandar un cambio, pero ello sin perjuicio del legítimo interés, del derecho que en favor del propietario se había originado, y entonces la Administración tiene un medio jurídico para resolver esta pugna del interés público y el privado; la expropiación de los derechos del particular sobre la edificación que resulta contraria a la higiene pública; pero no debe imponer un arbitrio con fin no fiscal.

Sabida es la dificultad de precisar los límites que separan el derecho subjetivo de los efectos reflejos del orden jurídico y estos a su vez de esta forma intermedia conocida entre los administrativistas por "interés legítimo", que es algo más que un efecto reflejo sin llegar a derecho subjetivo, diciéndose por algunos que es un derecho de esta clase debilitado en función del interés público.

De manera que si en el orden doctrinal resultan difuminados los contornos del interés legítimo, calcúlese cuál no será la dificultad de aplicar este precepto, tan lato, a la realidad de la vida, donde siempre surgen circunstancias y pormenores que no permiten un encaje completo en los conceptos.

Por eso ha de obrarse con toda cautela al establecer un arbitrio no fiscal que puede lesionar intereses legítimos que deben ser respetados.

f) Falta de otros medios coactivos. Si la Administración, en general, ha de ser pronta en el obrar; si su fundamental misión es obtener un fin práctico con la mayor celeridad, en cuanto el interés público lo reclama, resulta incuestionable que 
no debe retrasar la consecución del objeto perseguido utilizando medios indirectos cuando la Ley le otorga facultades para conseguirlo por los medios directos que a tal fin pone en sus manos. Si tiene medios coercitivos directos e inmediatos faltaría a su misión y cometido usando de otros medios cuando de este modo queda sin realizar la finalidad perseguida, o no se consigue con la prontitud que reclama el interés de la comunidad.

Cuando el propietario no hace desaparecer las causas que producen situaciones atentatorias a la higiene y salubridad en una construcción destinada a viviendas, bien porque no las dota de agua, cuando esto resulta obligatorio conforme a la Ley, bien porque no instala los servicios higiénicos de inodoro, 0 porque utiliza pozos sépticos cuando estos están proscritos de la zona en que se halla establecido el alcantarillado, etc.; si el propietario no revoca una fachada que está en pugna con el ornato público, con la estética urbana, con el decoro exigido "nic et nunc", según circunstancias múltiples en cada población diferentes que la autoridad municipal aprecia según su discreción; si no valla los solares sitos en el casco o en el Ensanche, contraviniendo las Ordenanzas de policía, etc., etc., es indudable que surge una obligación para la autoridad municipal de actuar con todos sus medios a fin de remediar la deficiencia y conseguir, cuanto antes, que ésta se corrija.

$\checkmark$ En el caso de que acuda a los arbitrios con fines no fiscales, es muy probable que el propietario calcule el importe del arbitrio (nunca muy elevado) y el costo de la obra a realizar. Como el pago del arbitrio le será económicamente menos oneroso, se avendrá a satisfacer éste y las deficiencias seguirán sin corregir. Con ello la moral, la higiene, la salubridad, el ornato de la población, la seguridad de las personas o de las cosas, etc., habrán salido perjudicados; y la Administración, aunque haya recau-. dado unas pesetas, no habrá cumplido su misión, que es poner en las debidas condiciones de urbanidad la población, consiguiendo el mejoramiento moral y material de su elemento humano.

Para llegar a ello debe usar la Administración de la acción directa, ordenando, conminando con sanciones e imponiendo 
éstas, si es preciso; subrogándose en el lugar del obligado y ejecutando subsidiariamente las obras necesarias a costa de aquél, exaccionando su importe por los medios de derecho público, llegando incluso al embargo y venta en pública subasta para hacerse pago de los gastos por todos conceptos causados.

El Decreto de 25 de enero de 1945 , en su artículo $48-3 .^{\circ}$, con acertada visión del problema, ha consignado el siguiente precepto digno de encomio: "No podrán establecerse arbitrios con fines no fiscales cuando los Ayuntamientos dispongan legalmente de otros medios coercitivos para lograr la finalidad del arbitrion.

Según el precepto transcrito, nuevo en nuestro derecho positivo, aunque no en la doctrina ni en la jurisprudencia, queda prohibido establecer este linaje de arbitrios cuando pueda la Administración usar medios coercitivos legales que directamente permitan conseguir el fin que se intente, consignando luego expresamente como uno de los motivos de impugnación contra el establecimiento de tal clase de arbitrios el de que la Administración disponga de tales medios de compulsión para llegar al fin que se pretende conseguir con el arbitrio no fiscal.

De acuerdo con esta restricción, que es digna de toda clase de alabanzas por cuanto depura el verdadero concepto doctrinal de los arbitrios con fines no fiscales (acaso mereciera distinta calificación el artículo 51, que no es objeto de nuestro comentario), habrán de eliminarse de las Ordenanzas fiscales de muchos Ayuntamientos la mayor parte de los que ahora tenían establecidos, pues su fin puede y debe, en una adecuada organización de los servicios, ser conseguido mediante el ejercicio de los medios coercitivos que la acción directa pone en manos de la Administración municipal.

N. Rodríguez Moro

Del Cuerpo de Secretarios de Administración Incal de $t^{\text {a }}$ categoria. 